\title{
Multiple Ground-Glass Opacities with Different Growth Rates in the Same Lobe of the Lung during the Follow-Up after the Resection of Pulmonary Adenocarcinoma: A Case Report
}

\author{
Takuro Yukawa, Katsuhiko Shimizu, Yuji Hirami, Riki Okita, Shinsuke Saisho, Ai Maeda, \\ Koichiro Yasuda, Masao Nakata \\ Department of General Thoracic Surgery, Kawasaki Medical School, Kurashiki, Japan \\ Email: tyukawa@med.kawasaki-m.ac.jp
}

Received 11 September 2014; revised 10 October 2014; accepted 9 November 2014

Copyright (C) 2014 by authors and Scientific Research Publishing Inc.

This work is licensed under the Creative Commons Attribution International License (CC BY). http://creativecommons.org/licenses/by/4.0/

(c) (;) Open Access

\section{Abstract}

The patient, a 77-year-old male, underwent right middle lobectomy for adenocarcinoma of the lung, pT1aNOM0, in November 2007. In November 2008, chest CT revealed two ground-glass opacities (GGOs) in the right lower lobe. In October 2009, both of these GGOs had increased in size, and three new GGOs were found. In July 2011, all of the five GGOs had increased in size and three new GGOs were found yet again. Right lower lobe S6 segmentectomy was performed on September 6, 2011, and histopathological examination revealed eight pulmonary adenocarcinomas in the right S6; all of them classified as pl0, ly0, v0, pT1aNOM0. Among the eight lesions, the doubling times of five were measured during the follow-up course, and the mean doubling time was $\mathbf{4 0 2}$ days. The mean doubling time of the lesions showing high c-erbB2 expression was significantly lesser than that of the lesions showing low c-erbB2 expression (273 days vs. 488 days, $p=0.047$ ). Despite being localized GGOs that had arisen in the same individual, it should be noted that the growth rate of the GGO lesions may vary according to the expression level of a molecular markers, and some GGO lesions may show rapid increase in size.

\section{Keywords}

Lung Adenocarcinoma, GGO, Immunohistochemical Staining 


\section{Introduction}

The incidence of multiple primary lung cancers has been reported to range from $0.7 \%$ to $15 \%$ in patients with lung cancer [1]-[6]. Small lung cancers visualized as localized ground-glass opacities (GGOs) on diagnostic imaging are frequently multiple, and are considered to grow relatively slowly [7]-[10]. We report a case with multiple GGOs in the same lobe of the lung, with different growth rates of the lesions.

\section{Case Report}

The patient was a 77-year-old male who underwent right middle lobectomy for adenocarcinoma of the lung, pT1aN0M0, in November 2007. Chest computed tomography (CT) in November 2008 carried out in the course of postoperative follow-up revealed two localized GGOs measuring $7 \mathrm{~mm}$, and $6 \mathrm{~mm}$ in diameter in S6 of the right lower lobe (Figure 1). On a chest CT obtained in October 2009, the two aforementioned GGOs had grown to $11 \mathrm{~mm}$ and $10 \mathrm{~mm}$, respectively, and three new GGOs measuring $8 \mathrm{~mm}, 7 \mathrm{~mm}$, and $7 \mathrm{~mm}$, had appeared in S6 of the right lower lobe. In another chest CT performed in October 2010, the first lesion had grown to $15 \mathrm{~mm}$ and the second to $13 \mathrm{~mm}$ in diameter, and each was found to contain an internal solid component. The three lesions found anew in 2009 had also slightly increased in size. In July 2011, the first lesion had grown to $17 \mathrm{~mm}$ in diameter, while the second of the lesions detected on the first follow-up CT remains unchanged in size at 13 $\mathrm{mm}$. Two of the three lesions first detected in 2009 had grown in diameter to $12 \mathrm{~mm}$ and $11 \mathrm{~mm}$, while the third remains unchanged at $9 \mathrm{~mm}$ in diameter, and new GGOs measuring $8 \mathrm{~mm}, 8 \mathrm{~mm}$, and $7 \mathrm{~mm}$ were observed yet again in S6 of the right lower lobe (Figure 2). A diagnosis of multiple lung cancers was made, and right lower lobe S6 segmentectomy was performed in September, 2011. Histologically, eight pulmonary adenocarcinomas were observed in the right S6, and all were classified as pl0, ly0, v0, pT1aN0M0; these eight lesions were considered to represent multiple lung cancers. Among the eight GGO lesions, the doubling times of five of the lesions were measured during the postoperative follow-up course, and the mean doubling time was 402 days (255 - 585 days). We examined the expression levels of p53, p16, p27, and c-erbB2 by immunohistochemical staining of the lesions (Figure 3) to evaluate the possible existence of a relationship between the tumor protein expression and the tumor doubling time. The mean doubling time in the lesions showing highc-erbB2 expression was significantly lesser than that of the lesions showing low c-erbB2 expression (273 days vs. 488 days, $p=0.047$ ). There were no relationships between the mean doubling time and the expression levels of p53, p16, or p27. The patient has shown no evidence of recurrence to date.

\section{Discussion}

Recent developments in various imaging techniques have increased our ability to identify synchronous multiple primary lung cancers. The incidence of multiple primary lung cancers has been reported to range from $0.7 \%$ to $15 \%$ among patients of lung cancer [1]-[6]. In particular, pulmonary adenocarcinomas that are visualized as localized GGOs on diagnostic imaging are known to be multiple frequently [6], and such adenocarcinomas are considered to grow relatively slowly [7]-[10]. Aoki et al. reported that the mean doubling time of Noguchi type $\mathrm{A}$ and $\mathrm{B}$ adenocarcinoma was 880 days [9]. Hasegawa et al. reported that the mean tumor doubling time of

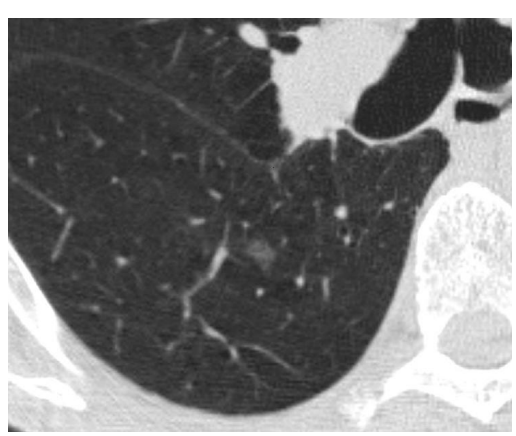

(a)

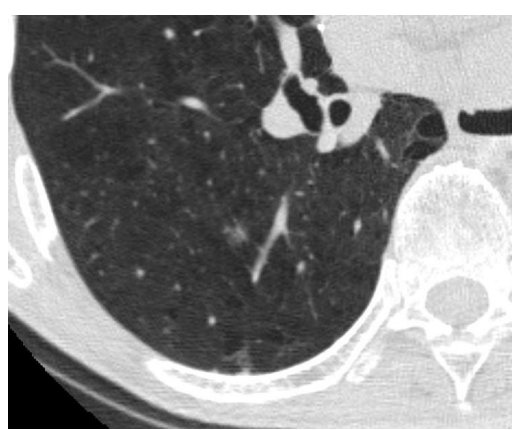

(b)

Figure 1. Chest CT in November 2008 showing two localized GGOs measuring $7 \mathrm{~mm}$ (a), and $6 \mathrm{~mm}$ (b) in diameter in S6 of the right lower lobe. 


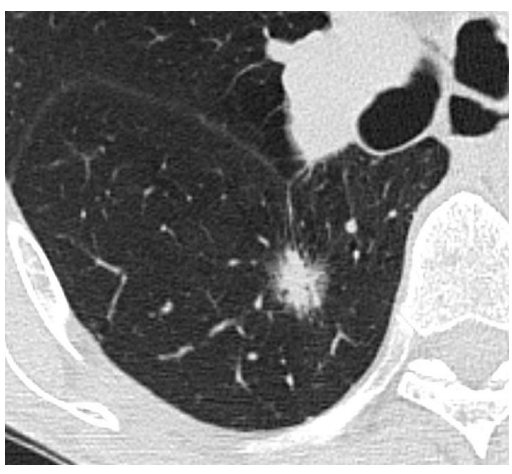

(a)

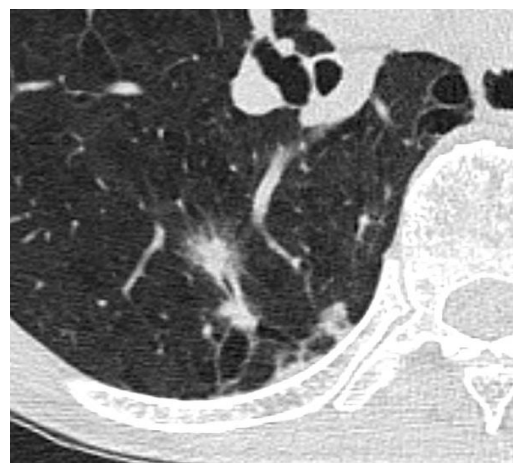

(b)

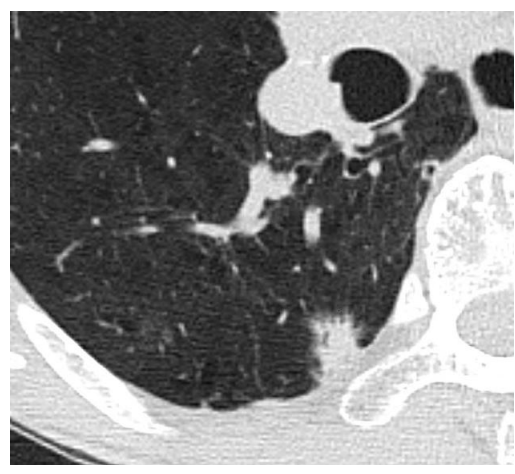

(c)

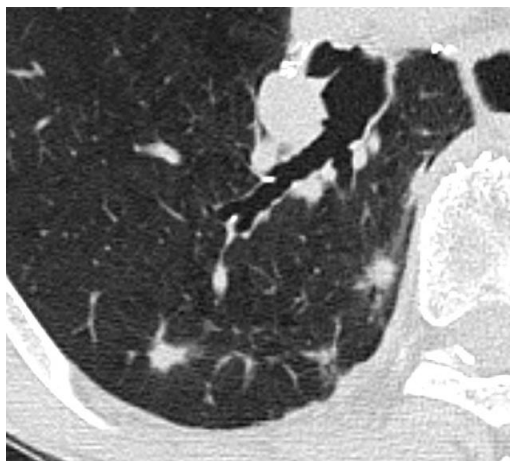

(d)

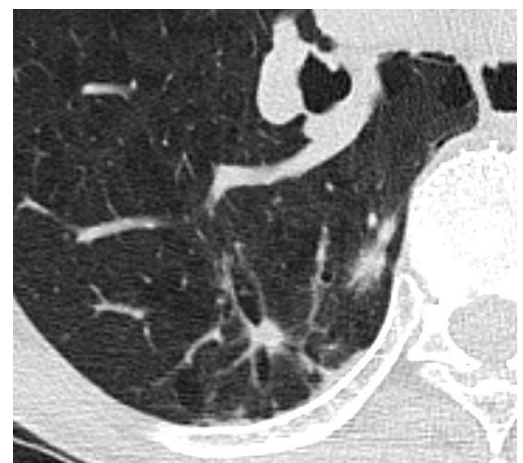

(e)

Figure 2. Chest CT in July 2011: (a) One of the two GGO lesions found in 2008 had increased in diameter from $7 \mathrm{~mm}$ to $17 \mathrm{~mm}$, and containing an internal solid component; (b) The other GGO found in 2008, also showing a solid component, had increased in diameter from $6 \mathrm{~mm}$ to $13 \mathrm{~mm}$; (c)-(e) Multiple lesions are visualized in $\mathrm{S} 6$ of the right lower lobe.

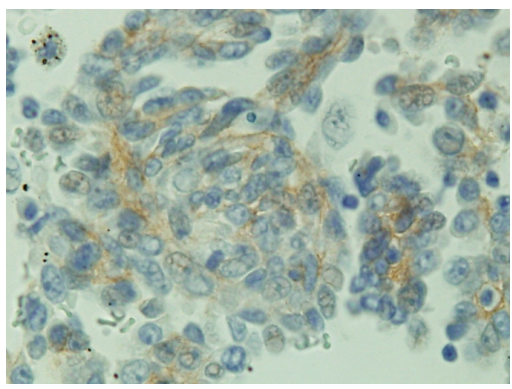

(a)

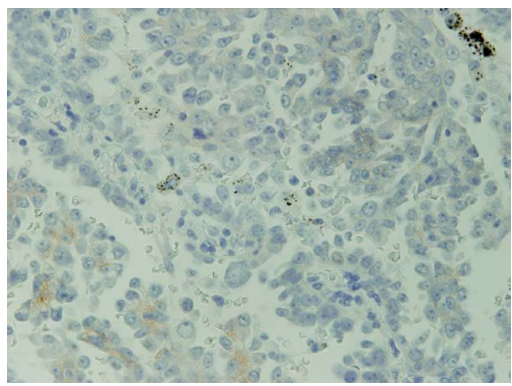

(b)

Figure 3. Immunohistochemical staining for c-erbB2; positive staining (a); negative staining (b).

GGO lesions was $813 \pm 375$ days [10]. Because biopsy of these lesions is sometimes difficult, these slowgrowing small GGO lesions are currently considered to be candidates for observation rather than for definitive diagnosis or treatment [11]. Hiramatsu et al. reported that some independent factors affecting the growth rates of GGO lesions include the initial tumor size and the history of lung cancer [8]. However, in our case, the mean doubling time of multiple GGO lesions was 402 days, and the shortest doubling time was 255 days, being shorter than that reported in the past.

There are two possible reasons for the rapid and uneven growth rates of GGO lesions in our case. First of all, these lesions were probably not multiple primary lung cancers, but pulmonary metastases (PM); secondly, they showed differences in molecular characteristics. In regard to the differential diagnosis between multiple lung cancers and PM, none of the lesions in this case showed evidence of lymphatic invasion or extrapulmonary metastases. According to the diagnostic criteria advocated by Martini [12], we considered the lesions as unlikely to 
be pulmonary metastases. On the other hand, for investigation of the tumor characteristics, we examined the expression levels of four different biomarkers in the tumors by immunohistochemical staining [13]-[19]. The results revealed a correlation between the growth rate and the expression level of c-erbB2, with the mean doubling time of the lesions in the high c-erbB2 expression group being significantly lesser than that of the lesions in the low c-erbB2 expression group. The high expression of c-erbB2 has been reported as an independent unfavorable prognostic factor in patients with non-small cell lung cancer [17]. It may be possible that differences in biomarker expression are reflected in the growth rates of GGO lesions. Despite being localized GGO lesions arising in the same individual, the findings in this case suggested that differences in the expression levels of biomarkers in individual GGOs may be associated with different growth rates of small GGO lesions.

\section{Conclusion}

Herein, we have reported a case of multiple primary adenocarcinomas with different growth rates in the same lobe of the lung. The findings in this case suggested the possibility of such lesions showing different growth rates depending on differences in the expression levels of molecular markers in the individual tumors. Despite being localized GGOs that had arisen in the same individual, it should be noted that the growth rate of the GGO lesions may vary according to the expression level of a molecular markers, and some GGO lesions may show rapid increase in size.

\section{References}

[1] Ferguson, M.K., DeMeester, T.R., DesLauriers, J., Little, A.G., Piraux, M., et al. (1985) Diagnosis and Management of Synchronous Lung Cancers. The Journal of Thoracic and Cardiovascular Surgery, 89, 378-385.

[2] Verhagen, A.F., van de Wal, H.J., Cox, A.L. and Lacquet, L.K. (1989) Surgical Treatment of Multiple Primary Lung Cancers. The Journal of Thoracic and Cardiovascular Surgery, 37, 107-111. http://dx.doi.org/10.1055/s-2007-1013919

[3] Lam, S., Macauley, C. and Palcic, B. (1993) Detection and Localization of Early Lung Cancer by Imaging Techniques. Chest, 103, 12-14. http://dx.doi.org/10.1378/chest.103.1_Supplement.12S

[4] Woolner, L.B., Fontana, R.S. and Cortese, D.A. (1984) Roentogenographically Occult Lung Cancer; Pathologic Findings and Frequency of Multicentricity during a 10-Year Period. Mayo Clinic Proceedings, 59, 453-466. http://dx.doi.org/10.1016/S0025-6196(12)60434-0

[5] Van Rens, M.T., Zanen, P., Brutel de La Riviere, A., Elbers, H.R., van Swieten, H.A., et al. (2000) Survival in Synchronous versus Single Lung; Upstaging Better Reflects Prognosis. Chest, 118, 952-958. http://dx.doi.org/10.1378/chest.118.4.952

[6] Nakata, M., Sawada, S., Yamashita, M., Saeki, H., Kurita, A., Takashima, S., et al. (2004) Surgical Treatment for Multiple Primary Adenocarcinoma of the Lung. Annals of Thoracic Surgery, 78, 1194-1199. http://dx.doi.org/10.1016/j.athoracsur.2004.03.102

[7] Nakata, M., Saeki, H., Takata, I., Segawa,Y., Mogami, H., et al. (2002) Focal Ground-Glass Opacity Detected by Low-Dose Helical CT. Chest, 121, 1464-1467. http://dx.doi.org/10.1378/chest.121.5.1464

[8] Hiramatsu, M., Inagaki, T., Inagaki, T., Matsui, Y., Satoh, Y., Okumura, S., et al. (2008) Pulmonary Ground-Glass Opacity (GGO) Lesions-Large Size and a History of Lung Cancer Are Risk Factors for Growth. Journal of Thoracic Oncology, 3, 1245-1250. http://dx.doi.org/10.1097/JTO.0b013e318189f526

[9] Aoki, T., Nakata, H., Watanabe, H., Nakamura, K., Kasai, T., Hashimoto, H., et al. (2000) Evolution of Peripheral Lung Adenocarcinomas: CT Findings Correlated with Histology and Tumor Doubling Time. American Journal of Roentgenology, 174, 763-768. http://dx.doi.org/10.2214/ajr.174.3.1740763

[10] Hasegawa, M., Sone, S., Takashima, S., Li, F., Yang, Z.G., Maruyama, Y., et al. (2000) Growth Rate of Small Lung Cancers Detected on Mass CT Screening. The British Journal of Radiology, 73, 1252-1259. http://dx.doi.org/10.1259/bjr.73.876.11205667

[11] Libby, D.M., Smith, J.P., Altorki, N.K., Pasmantier, M.W., Yankelevitz, D. and Henschke, C.I. (2004) Managing the Small Pulmonary Nodule Discovered by CT. Chest, 125, 1522-1529. http://dx.doi.org/10.1378/chest.125.4.1522

[12] Martini, N. and Melamed, M.R. (1975) Multiple Primary Lung Cancers. Journal of Thoracic and Cardiovascular Surgery, 70, 606-612.

[13] Dobashi, K., Sugio, K., Osaki, T., Oka, T. and Yasumoto, K. (1997) Micrometastatic p53-Positive Cells in the Lymph Nodes of Non-Small-Cell Lung Cancer: Prognostic Significance. Journal of Thoracic and Cardiovascular Surgery, 114, 339-346. http://dx.doi.org/10.1016/S0022-5223(97)70178-8

[14] Taga, S., Osaki, T., Ohgami, A., Imoto, H., Yoshimatsu, T., Yoshio, I., et al. (1997) Prognostic Value of the Immuno- 
histochemical Detection of p16INK4 Expression in Non-Small Cell Lung Carcinoma. Cancer, 80, 389-395. http://dx.doi.org/10.1002/(SICI)1097-0142(19970801)80:3<389::AID-CNCR6>3.0.CO;2-N

[15] Tsukamoto, S., Sugio, K., Sakada, T., Ushijima, C., Yamazaki, K. and Sugimachi, K. (2001) Reduced Expression of Cell-Cycle Regulator p27 ${ }^{\text {Kip1 }}$ Correlates with a Shortened Survival in Non-Small Cell Lung Cancer. Lung Cancer, 34, 83-90. http://dx.doi.org/10.1016/S0169-5002(01)00216-1

[16] Sugio, K., Ishida, T., Yokoyama, H., Inoue, T., Sugimachi, K. and Sasazuki, T. (1992) Ras Gene Mutations as a Prognostic Marker in Adenocarcinoma of the Human Lung without Lymph-Node Metastasis. Cancer Research, 52, 29032906.

[17] Osaki, T., Mitsudomi, T., Oyama, T., Nakanishi, R. and Yasumoto, K. (1995) Serum Level and Tissue Expression of c-erbB-2 Protein in Lung Adenocarcinoma. Chest, 108, 157-162. http://dx.doi.org/10.1378/chest.108.1.157

[18] Mitsudomi, T., Hamajima, N., Ogawa, M. and Takahashi, T. (2000) Prognostic Significance of p53 Alterations in Patients with Non-Small Cell Lung Cancer: A Meta-Analysis. Clinical Cancer Research, 6, 4055-4063.

[19] Otterson, G.A., Kratzke, R.A., Coxon, A., Kim, Y.M. and Kaye, F.J. (1994) Absence of p16INK4 Protein Is Restricted to the Subset of Lung Cancer Lines that Retains Wildtype RB. Oncogene, 9, 3375-3378. 
Scientific Research Publishing (SCIRP) is one of the largest Open Access journal publishers. It is currently publishing more than 200 open access, online, peer-reviewed journals covering a wide range of academic disciplines. SCIRP serves the worldwide academic communities and contributes to the progress and application of science with its publication.

Other selected journals from SCIRP are listed as below. Submit your manuscript to us via either submit@scirp.org or Online Submission Portal.
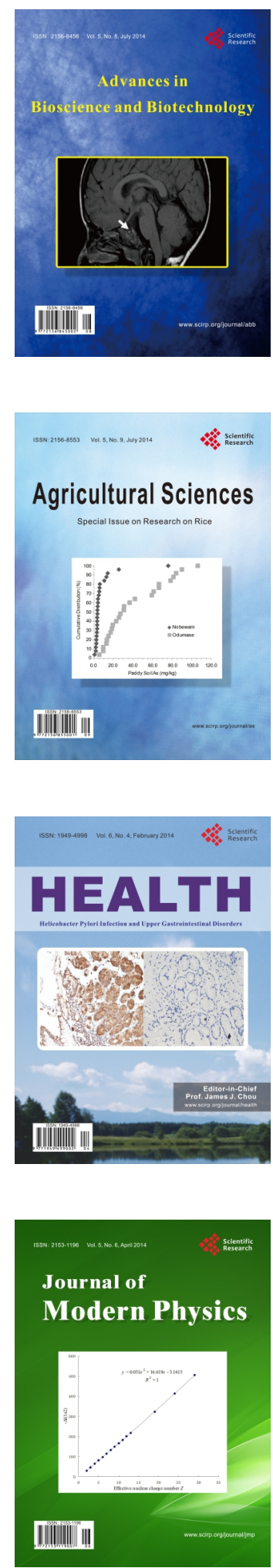
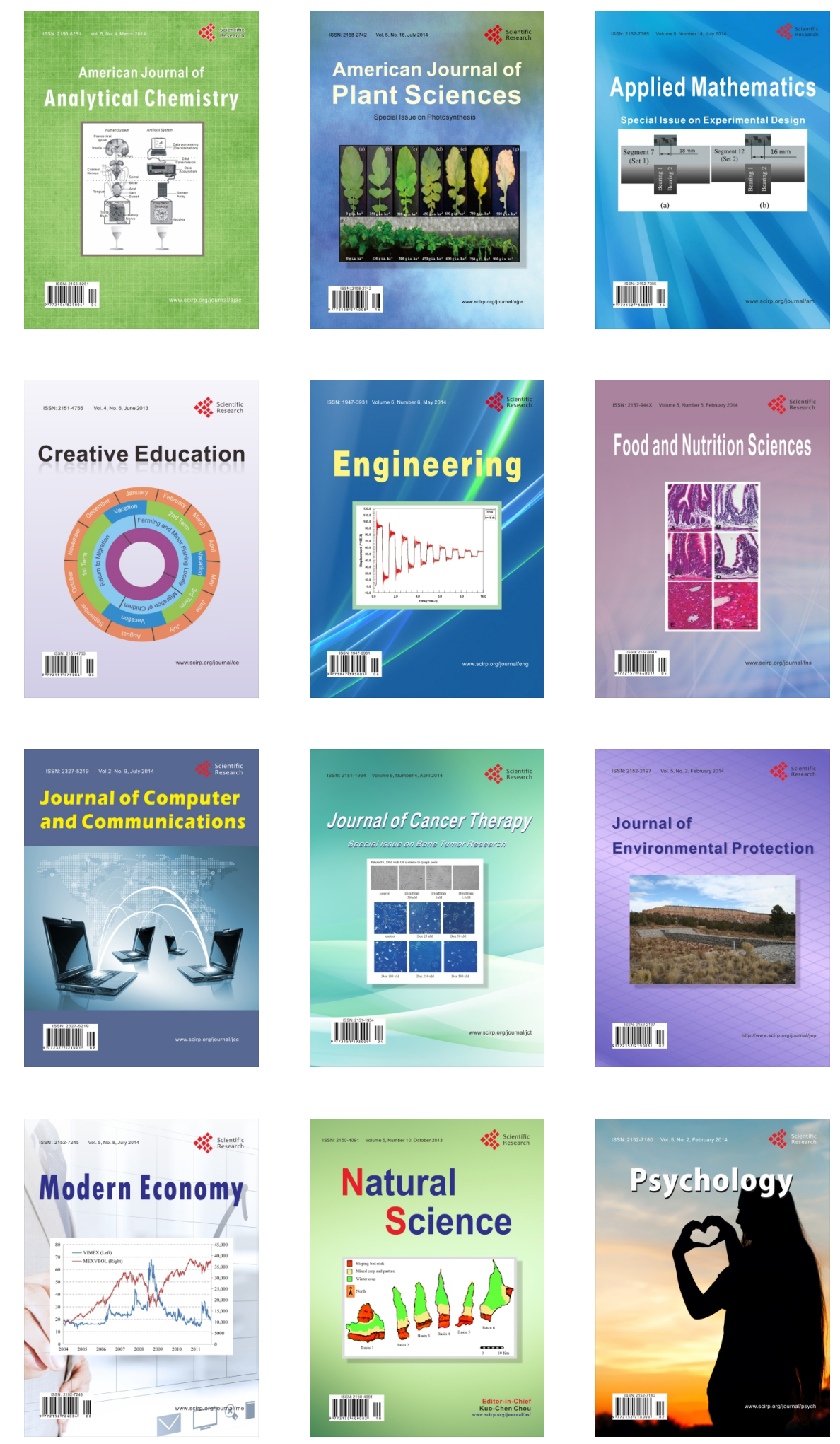